\title{
Mismidad y diferencia en el devenir histórico del arte Los enfoques de Gilles Deleuze y Arthur Danto
}

\author{
Sameness and Difference in the Historical \\ Development of Art \\ Gilles Deleuze and Arthur Danto's Approaches
}

\author{
Juan P. Sosa \\ sosajuanp@gmail.com \\ Mariano O. Martínez Atencio \\ cuatroestados@gmail.com \\ Universidad Nacional \\ de Mar del Plata. Argentina \\ Recibido: 22/10/2018 \\ Aceptado: 13/2/2019
}

\begin{abstract}
Resumen
La historia del arte se encuentra signada por una serie de alteraciones y de transformaciones que configuran su fisonomía. Podría afirmarse que la misma no constituye sino la suma total de esos cambios. Tal desarrollo acompañó la búsqueda de la diferencia como elemento constitutivo. Así, desde la propuesta teórica de Arthur Danto, la historia del arte habría finalizado una vez que la experimentación arrojó su definición específica desde la filosofía; mientras que para el enfoque de Gilles Deleuze la historia del arte no es más que el conjunto de condiciones del que es necesario huir para la creación de lo nuevo, es decir, lo diferente. El presente ensayo busca articular dos lecturas disímiles bajo una problemática común: el concepto de diferencia como constitutivo del arte.
\end{abstract}

\section{Palabras clave}

Filosofía del arte; estética; historia; Danto; Deleuze
Philosohpy of art; Aesthetics; History; Danto; Deleuze

\section{Keywords}

\begin{abstract}
The history of art is marked by a series of alterations and transformations that shape its physiognomy. For some approaches, the historical impulse of art accompanied the search for difference as a constitutive element. Thus, from the theoretical proposal of Arthur Danto, the history of art would have reached its completion once that such experimentation threw its specific definition from the philosophy occupied in its analysis; whereas for Gilles Deleuze's approach the history of art is only the set of conditions from which it is necessary to flee for the creation of the new, that is, the different. The present essay seeks to articulate two dissimilar readings under a common problem: the concept of difference as constitutive of art.
\end{abstract}


Suele pensarse en la historia del arte como la búsqueda o el rastreo de aquellas notas comunes a una pluralidad de ejercicios a menudo contrapuestos. El resultado permite identificar elementos desvinculados en su origen, pero unificados desde el enfoque categorial que el concepto inaugura. Sin ahondar en las múltiples dificultades a las que esto puede dar lugar, el recorrido que aquí se propone apunta a destacar algunas continuidades, precisamente en torno al concepto de la diferencia, tan esquivo a aquel impulso de homogeneidad propio de la historia del arte.

Según esta lectura, los grandes relatos que configuran el desarrollo histórico de las artes singularizan un enfoque que privilegia la mismidad por sobre las diferencias. Esto es, que busca socavar aquellas distinciones singulares entre cada evento, acción u objeto procurando una correspondencia afín a una narración. Sin embargo, el ejercicio promovido desde cada una de las artes particulares no deja de cuestionar cada uno de estos intentos de clasificación narrativa al instalar la novedad y renovar permanentemente la pregunta por la naturaleza de lo artístico.

Un primer momento del presente ensayo se ocupará del pensamiento filosófico de Gilles Deleuze con eje en el concepto de diferencia. Para el autor de Diferencia y Repetición (2009a), las artes y la filosofía son formas de pensamiento que encuentran un problema en común en la producción de lo nuevo ante la contrariedad de la representación. La diferencia, o lo nuevo, se presenta como aquello que no puede ser pensado desde el modelo de la representación ni clasificado por la historia con su teleología y grandes continuidades.

En un segundo momento, la perplejidad por Arthur Danto ante la obra Brillo Box (1964), del artista plástico Andy Warhol, servirá de escenario para desarrollar las principales ideas del autor de la transfiguración del lugar común [1981] (2004) como interrelación de tres ejes fundamentales: historicismo, esencialismo y pluralismo. Así, el programa dantiano arroja una definición de lo artístico que habilita un escenario pluralista de su desarrollo actual al tiempo que sentencia la finalización de la historia del arte como cese de su impulso cognitivo.

Finalmente, se recuperarán aquellas notas compartidas y en tensión entre ambos enfoques, a fin de reactualizar la lectura acerca del concepto de la diferencia, sustancial a la obra de arte y al desarrollo evolutivo del fenómeno y de la práctica de las artes. 


\title{
Gilles Deleuze: pensar la diferencia, crear lo nuevo
}

\author{
"Lo que me interesa son las relaciones entre las artes, \\ la ciencia y la filosofía. No hay privilegio alguno de una de \\ estas disciplinas sobre otra de ellas. Todas son creadoras.» \\ Gilles Deleuze (2014)
}

Hablar acerca de la relación entre la filosofía y las artes en el pensamiento de Gilles Deleuze implica, necesariamente, un cierto recorrido por algunos conceptos fundamentales de su pensamiento y su complejo entramado. La característica fundamental de su filosofía es la búsqueda incansable de una inmanencia radical. En este sentido, cuando Deleuze se relaciona con las artes no es para capturarlas en formas estancas y preestablecidas, sino para captarlas en su devenir; esto quiere decir que no arriba a ellas proponiendo una estética en sentido clásico. No pretende desarrollar una filosofía del arte en la que la filosofía reflexione sobre el arte, que hable en su nombre y en lugar de las diferentes expresiones artísticas. Pues «nadie necesita de la filosofía para reflexionar sobre cualquier cosa» (Deleuze \& Guattari, 2009, p. 12), y el hecho de reflexionar sobre algo no nos convierte en filósofos. Asimismo, las filosofías del arte establecen problemas prefijados en torno a cuestiones artísticas que incurren en estéticas del espectador, del juicio, sustentadas en un núcleo subjetivo, social, fenomenológico, analítico o semántico. En definitiva, estéticas de la representación y del reconocimiento que se pronuncian como una disciplina que produce y reproduce la historia del arte como la historia de las formas en su correspondencia sensible. Estéticas que restablecen problemas prefijados para repuestas prefabricadas, aplicadas en dominios impropios, inadecuados y adecuándolos a su propia problemática. En este caso, la filosofía se reconoce en los problemas del arte.

La filosofía no es, entonces, la reflexión sobre algo diferente como son las artes, pues al igual que estas tiene su propia autonomía, actividad y soporte. En ¿Qué es la filosofía? (2009), Gilles Deleuze y Félix Guattari manifiestan que las artes, como la filosofía o la ciencia, son formas de pensamiento que se cruzan, se entrelazan, sin jerarquía y sin llegar a una síntesis ni a una identificación. Así, las artes son formas de pensamiento independientes y singulares que no necesitan de la filosofía para reflexionar sobre su propia actividad. Hay un pensamiento en los grandes artistas; pintar, escribir, componer una obra son una creación viva del pensamiento (Deleuze \& Guattari, 2009). En cualquier caso, 
1 «Los perceptos ya no son percepciones, son independientes de un estado de quienes los experimentan; los afectos ya no son sentimientos o afecciones, desbordan la fuerza de aquellos que pasan por ellos» (Deleuze \& Guattari, 2009, pp. 164-165).

2 El abecedario de Gilles Deleuze transcripción del programa de arte Metrópolis del canal de arte franco-alemán (1995) (Programa coordinado por PierreAndré Boutang, discusiones filmadas en 1988 por Claire Parnet). Traducción: Raúl Sánchez Cedillo. tanto en las artes como en la filosofía, no se piensa de gusto o de buena gana, sino por necesidad, porque algo fuerza a pensar. Todo parte de la sensibilidad, de un encuentro, con la presencia de algo que lo interpela, que lo engendra. En este sentido, el pensamiento comienza cuando es afectado, con la diferencia, con una presencia que fractura la unidad de lo dado y escapa a la representación. Pensar es crear, «es siempre producir líneas y figuras de diferenciación en el pensamiento» (Deleuze, 2009a, p. 379), es engendrar pensamiento en el pensamiento. Pero mientras la filosofía piensa el concepto, el arte pinta, esculpe, compone o escribe sensaciones (Deleuze \& Guattari, 2009). Es decir, son igualmente creadoras, pero mientras que a la filosofía le corresponde la creación de conceptos, al arte le corresponde la creación de bloques de sensación, bloques de afectos y perceptos. ${ }^{1}$ Crear conceptos es tan difícil como crear nuevas combinaciones visuales, sonoras; en definitiva, producir nuevas sensaciones. De esta manera, aquello que resuena en el encuentro entre arte y filosofía es la actividad común de la creación, enmarcada en la pregunta por lo nuevo, indisociable de los procesos de individuación que la soportan, como así también, las individuaciones que emergen de este proceso.

Lo nuevo o la diferencia es el criterio de todo pensamiento, de toda obra ya sea filosófica o artística. «Para la filosofía, para la pintura, para todo... para el arte, entonces, ya sea la canción popular o lo demás [...] y es exactamente lo mismo: ¿qué sucede nuevo?» (Boutang, 1996). ${ }^{2}$ Después de todo, no hay razón para escribir filosofía si no hay conceptos nuevos que crear, y no hay razón para escribir, esculpir o pintar si no hay algo nuevo que componer, nuevas figuras de diferenciación que producir. En este sentido, si cabe pensar una estética deleuziana es una estética inorgánica que aborda, como expresa René Schérer (2012), las lógicas secretas de la producción de sensibilidades nuevas. Una estética en la cual la filosofía se encuentra con las artes en la problemática de la creación y lo sensible, en ese espacio intermezzo de la creación de lo nuevo y la producción de sensibilidades. Siendo esto, «un encuentro quizás sea lo mismo que un devenir» (Deleuze, 2013, p. 11), algo que sucede entre, un movimiento sin punto de partida ni de llegada en una relación dispar sin términos que se intercambien. Así, un encuentro o un devenir es siempre problemático, es aquello que fuerza a pensar. Por lo que, en este encuentro, las artes son ese fuera de la filosofía que impulsa la creación de conceptos. Pero si la creación es el punto de encuentro entre las artes y la filosofía, su problema en común es el pensamiento de la representación. Pues la representación es incapaz de pensar lo nuevo, o sea, la diferencia. 
De esta manera, en Diferencia y Repetición (2009a), Deleuze se aboca a pensar la diferencia en sí misma y a crear una nueva filosofía de la diferencia. Para ello requiere de la creación de un nuevo concepto de diferencia y un nuevo concepto de repetición liberados del modelo de la representación. Este modelo se presenta como incapaz de pensar la diferencia en sí misma, puesto que subordina la diferencia a las exigencias de la identidad, a los requisitos del concepto y a las demandas de lo mismo. El objetivo de Deleuze es desprenderse de la tradición filosófica que concibe la representación como aquello que remite las diferencias al concepto y que se extiende desde Sócrates y Platón a la dialéctica hegeliana (Deleuze, 2009a).

En Lógica del sentido (2008a), particularmente en el apéndice «I simulacro y filosofía antigua», se afirma que la representación se sustenta sobre la dualidad modelo-copia; esto es, un modelo original (ideal) y su copia como una representación del modelo. En este caso, la diferencia se sustrae negativamente de la relación modelo-copia a la cual queda siempre remitida. Pero además del modelo y de la copia están los simulacros, que se constituyen a partir de una primera diferencia (la copia) y componen una diferencia de la diferencia que se aleja cada vez más del modelo. Por lo que los simulacros no mantienen una relación directa con el modelo del cual se diferencian. Estos no son solo una mala copia, que al alejarse tanto del modelo original se vuelven irreconocibles, motivo por el que son desechados por el pensamiento platónico, sino que ponen en cuestión la noción misma del modelo y la copia. Por su parte, la dialéctica hegeliana concibe la diferencia también de forma negativa en el momento de la contradicción, que finalmente es remitida a la identidad y es subsumida en la síntesis. La diferencia es reducida a la polaridad de dos momentos y se disuelve, finalmente, en la identidad de un tercero. Deleuze rescata a través de Lucrecio los simulacros como esas diferencias de las diferencias que se han escindido del original y constituyen efectos de superficie, incorporales efectos de choques entre cuerpos. Los simulacros son la pura diferencia que se desplaza por la superficie sin dejarse capturar por el modelo ni la copia (Deleuze, 2008a).

Así, Deleuze va a liberar la diferencia de la relación modelocopia y de la contradicción dialéctica, para pensarla positivamente como una flotación perpetua. Para ello, es necesario invertir el platonismo o el pensamiento de la representación. Invertir el platonismo es, negativamente, rechazar la idea o el modelo en relación con una copia como aquello que subordina la diferencia a lo mismo, a la identidad o a la semejanza. Y, positivamente, hacer de la diferencia una afirmación en perpetua repetición. Si pensar 
es crear o producir líneas y figuras de diferenciación, aquello que se crea no es sino lo nuevo. La diferencia o lo nuevo es aquello que no es posible reconocer, identificar o predecir. Lo nuevodiferente irrumpe en un campo de representación para dislocarlo, para fragmentarlo o romperlo, y producir, a su vez, sentidos y valores nuevos. De esta manera, no es algo que esté dado, no es nada a priori, sino aquello que no cesa de mutar, de diferir cada vez que se repite (diferencia de diferencia). Entonces, engendrar pensamiento en el pensamiento es liberarlo de los obstáculos internos que lo apresan, que lo capturan o contienen y construyen una imagen de sí mismo que lo desnaturaliza y lo vuelve inactivo.

A esta imagen desnaturalizada del pensamiento, entregada al sentido común, a los postulados de la representación, Deleuze la denomina imagen dogmática del pensamiento. Ciertamente es una constante en los escritos del filósofo francés la temática de una imagen del pensamiento que impediría pensar. Desde Nietzsche y la filosofía (2008b), Proust y los signos (1970), y Diferencia y Repetición (2009a) insiste en la naturaleza del pensamiento. Es el problema que Deleuze retoma y hace suyo de la filosofía de Nietzsche, el problema de liberar el pensamiento de los obstáculos que lo aprisionan, que lo imposibilitan. La imagen dogmática es la entrega del pensamiento a formas inactivas que se expresan, según la tradición lo ordena, en la filosofía de la época, que nos exige pensar de un modo determinado, de acuerdo a un estilo y a un régimen de producción. En cambio, renovar la imagen de lo que significa pensar es la tarea que todo gran pensador debe llevar a cabo para impulsarse hacia un nuevo pensar. De esta manera, pensar es crear aquello que no puede ser pensado desde el punto de vista del sentido común o de la representación, es decir, la diferencia o lo nuevo.

Crear líneas conceptuales o figuras estéticas de diferenciación es, en definitiva, crear ideas filosóficas o artísticas. Un concepto es una idea filosófica, un bloque de sensación de perceptos-afectos es una idea artística. Estas ideas son conjuntos de relaciones diferenciales o multiplicidades problemáticas. Una idea como objeto de diferencias, tanto artísticas como filosóficas, es lo que violenta el pensamiento y lo activa, lo origina. Luego, esta idea-problema se actualiza por líneas o series de diferenciación que componen nuevas ideas-problemas $y$, de esta manera, se prolongan las series. Una idea-problema artística puede actualizarse en una línea filosófica que, a su vez, se actualiza en nuevas ideas-problemas. Deleuze piensa en términos de líneas y series que se interfieren, en términos de relaciones de intercambio y resonancia por razones intrínsecas en cada caso. En este sentido, la filosofía y las artes son como líneas melódicas ajenas unas a otras, pero que no dejan 
de interferirse (Deleuze, 2014). En este caso, es la representación, incapaz de pensar la diferencia o lo nuevo en sí mismo, o la diferencia que rompe con la representación y no cesa de actualizarse, uno de los puntos en el que la línea filosófica intercepta la línea artística.

«Ningún arte, ninguna sensación han sido jamás representativos" (Deleuze \& Guattari, 2009, p. 195). En Francis Bacon. Lógica de la sensación (2009b) Deleuze afirma, como en la cita recién mencionada, que ningún arte es figurativo, mimético, narrativo o representativo. Si bien puede pasar por la representación, no se reduce a ella. En rigor, el concepto de arte es solo un concepto nominal que reúne a una comunidad de las artes, es decir, problemas muy diferentes que encuentran soluciones en artes heterogéneas (Deleuze \& Guattari, 2006), lo que no impide hablar de una problemática común a las diferentes expresiones artísticas. Este problema común es el de captar las fuerzas, hacer visibles fuerzas que no lo son o hacer audibles fuerzas inaudibles; en definitiva, hacer sensibles fuerzas insensibles. Lo nuevo-diferente en las artes es lo insensible que se hace sensible o, lo que es lo mismo, lo no sentido que alcanza la sensación. Opuesta al cliché (lo fácil, acabado) y a lo sensacional (lo espontáneo), la sensación no remite al sujeto (espectador o artista) ni al objeto (obra), sino que es las dos cosas indisolublemente. Es en este sentido que se habla de bloques de perceptos-afectos. La sensación es lo contrario de lo que se supone que el objeto representa, más bien, es lo que pasa de un orden a otro. Además, no hay sensaciones de diferentes órdenes, sino diferentes órdenes de una única y misma sensación. Estos diferentes órdenes o niveles de sensación remiten a los diferentes órganos de los sentidos en contacto con una potencia vital más profunda que los sentidos, que desborda todo dominio y lo atraviesa. Esa potencia es el ritmo o la unidad rítmica de los sentidos (Deleuze, 2009b).

En este punto tenemos que introducir un concepto fundamental como es el de cuerpo sin órganos. Pues bien, aquella potencia o unidad rítmica de los sentidos más allá del organismo es el cuerpo sin órganos. Este es un cuerpo intenso, intensivo, recorrido por niveles o umbrales de variación. La sensación rompe los límites de la actividad representativa orgánica hacia el cuerpo intenso sin órganos. Más profunda que cualquier dato representativo u orgánico, la sensación es intensiva, y como intensidad es una diferencia que atraviesa niveles de variación. En este sentido, la intensidad como diferencia es la razón de lo sensible; dicho de otro modo, la diferencia es intensiva o de intensidad y constituye el ser de lo sensible, el límite propio de la sensibilidad. Es lo insensible que no puede ser sino sentido, aquello que conduce del límite de lo 
sentidos al límite del pensamiento, del límite de lo que solo puede ser sentido a lo que solo puede ser pensado. Es decir, el punto o la fractura que fuerza a pensar, que fuerza a sentir (Deleuze, 2009b). Las diferentes expresiones artísticas en su común problema de captar fuerzas insensibles se proponen despejar una presencia debajo de la representación. Esa presencia, que no es otra cosa que la sensación, al mismo tiempo libera los órganos de sus funciones orgánicas o un cuerpo intenso bajo el cuerpo orgánico. En resumidas cuentas, las artes, entonces, no reproducen o inventan formas, sino que captan fuerzas que son condición de la sensación, debido a que una fuerza se ejerce sobre un cuerpo para que tenga lugar la sensación (Deleuze, 2009b). En este sentido, a la violencia de la representación Deleuze le opone la violencia de la sensación o la diferencia.

Hay un devenir artista o un devenir filósofo, en definitiva, un devenir pensador que nada tiene que ver con la historia de la filosofía o la historia del arte. Un devenir pasa por aquellos lugares que la historia no logra clasificar (Deleuze, 2013), por aquellas presencias que se despejan y los cuerpos intensos que se liberan. El devenir no es la historia, es el acontecimiento en el que centellea lo diferente o del que emerge lo nuevo y escapa a la historia, el simulacro que desquicia la representación. La historia, con sus continuidades y teleologías, designa el conjunto de condiciones de las que hay que desprenderse para devenir o, lo que es lo mismo, para pensar, para crear algo nuevo. Después de todo, pensar es el acto intempestivo que escapa a los postulados de una época, que provoca una desconexión, un desfasaje. Así, el verdadero problema del pensamiento es el de su devenir, la problemática de liberarlo de los obstáculos internos que lo imposibilitan, para crear fuera de las formas preconcebidas hacia un nuevo modo de pensar o diferentes formas de sentir.

3 Motivado por la publicación de las Investigaciones Filosóficas (1953), de Ludwig Wittgenstein, un grupo de teóricos y filósofos vinculados al ámbito de la reflexión artística y estética consagró diversos esfuerzos en mostrar la imposibilidad de definir el arte. Sus argumentos recuperan la naturaleza abierta del concepto de arte; el tono marcadamente descriptivo que deberá asumir cualquier intento por caracterizarlo; o incluso la multiplicidad de instancias de aplicación a que da lugar el mismo. Para una adecuada comprensión de estas posiciones, véanse William Kennick (1958), Morris Weitz (1956) y Paul Ziff (1953).

\section{Arthur Danto: los indiscernibles como frontera del arte}

Hablar acerca de la filosofía del arte de Arthur Danto es, de algún modo, involucrarse con la narración de un entramado conceptual. Resulta casi imposible referirse a algún concepto de su propuesta teórico-filosófica sin tocar siquiera lateralmente el resto de los conceptos involucrados en ella. Dicho esto convendrá precisar el alcance de sus postulados centrales con vistas a obtener una lectura siquiera global de su planteo.

Heredero de un debate acerca de la imposibilidad de definir el arte, ${ }^{3}$ su posición dará lugar a un marcado esencialismo como intento de acabar con esa discusión y asumirá la proclama de una instancia de clausura para el desarrollo histórico del arte en lo que 
4 La obra de Warhol, inscripta en lo que se conoce como arte pop, asume a la perfección la apariencia de su referente comercial del supermercado. Brillo era un producto comercial (jabón) destinado a consumo masivo presente en las casas de expendios de la época. La caja de Warho se revela exactamente igual, en apariencia, a su par no-obra de arte del supermercado —diseñada por James Harvey-. Warhol presentó su obra originalmente en 1964 en la Stable Gallery de Manhattan. Hoy puede verse algún ejemplar de la misma en e MOMA (Museum of Modern Art) de Nueva York (Warhol, 1964) se conoce como su polémica tesis sobre el fin del arte. Tal vez sea esta, su tesitura acerca de la historia del arte, o mejor, de su finalización, la que convenga considerar en primer lugar a fin de que regule el recorrido conceptual que se irá desplegando conforme avance su exposición.

La particularidad de su relato acerca de la historia del arte involucra la captación de un impulso inmanente en lo que considera un progreso hacia el autoconocimiento. Es decir, la historia del arte sería el recorrido trazado por este hasta alcanzar la instancia de comprensión de sí. Ahora bien, puesto que según Danto tal cosa ocurriría con la efectiva posesión de la definición del arte, una vez obtenida ésta el arte deviene esencialista (desde su definición), post-histórico (desde su historiografía) y pluralista (desde su estilística). Esto es, con la clave definicional a la mano es posible articular su abarque y hacerlo extensivo a las innúmeras manifestaciones que pueblan el escenario del arte en materia de producción de obras y habilitar, consecuentemente, un período de absoluta pluralidad.

El recorrido parte de situaciones donde la semejanza se hace patente hasta el hartazgo. Por ello, suele considerarse que el planteo dantiano se sostiene desde una lógica del parecido inusual entre dos objetos, dos cosas o dos eventos. Aquellas situaciones en que se dan dos instancias de algo en apariencia idénticas, pero pertenecientes a dominios categoriales presuntamente diferentes, han constituido un recurso fundamental en su obra. En términos estrictamente vinculados al arte, el par utilizado por el autor se encuentra constituido por la famosa obra de arte pop de Andy Warhol, Brillo Box de 1964, y su contrapartida del supermercado, Caja de Brillo. ${ }^{4}$ Para Danto se trató de un juego en el que participó una lógica de homólogos indiscernibles. Sin embargo, todo el fundamento que se desprende del desarrollo teórico de su propuesta filosófica supone la búsqueda de la diferencia subyacente a dicho juego.

El hecho de que ambos objetos (ambas cajas) se parezcan hasta la confusión supone, empero, la necesidad de dar con la diferencia que habilita el reconocimiento. Dicho de otro modo, si ambos objetos lucen idénticos pero pertenecen a categorías ontológicas - como piensa Danto (1964) - distintas, entonces debe haber algo que los diferencie y, por lo tanto, será tarea específica del filósofo impulsar su hallazgo.

Así, el desarrollo histórico del arte, según este enfoque, supo avanzar su impulso progresista hasta arribar a un momento en que desde el ejercicio mismo de su práctica promovió la pregunta correcta por su naturaleza. Tal afirmación se corresponde con la lectura dantiana que identifica dos grandes paradigmas teóricos 
5 Está claro que según el enfoque dantiano la historia del arte comienza con la progresiva configuración del sistema de las artes que acabará cristalizando en lo que se conoce como sistema de las Bellas Artes, antes de lo cual no habrían existido diferencias sustantivas entre el ahora arte y las artesanías, y luego de lo cual no habrá más relato legitimador dominante. en el devenir del arte: el mimético y el modernista. Según el primero, el progreso del arte se vio signado por el afán de alcanzar grados cada vez más depurados de dominio técnico en la representación de la realidad extrartística. Este habría sido el paradigma más extendido en la historia, sostenido hasta muy avanzada la modernidad y desde el Renacimiento aproximadamente. Para el segundo, con epicentro en los últimos años del siglo XIX, el impulso creativo tuvo que ver con depurar los distintos lenguajes plásticos de las diversas artes. Aquí, el afán de indistinción en la representación disminuyó, según Danto, para dar lugar a la evidencia del soporte material de cada lenguaje artístico. Es decir, la representación ya no buscó fidelidad con sus modelos, sino evidencia de su concreción de ser artificial. ${ }^{5}$

Según Danto (1981), en el seno del paradigma modernista - probablemente como finalización de su impulso- se desarrollaron los grandes movimientos de vanguardias históricos de principios de siglo XX. Cada uno de estos procuró dotar al arte de una definición y un modo específico de producción de obra y, así, diferenciarlo de los estilos restantes. Al mismo tiempo, dejaron entrever la necesidad de definición, aunque inadvertidamente cuestionada. Dicho programa o paradigma modernista halló su finalización promediando el siglo XX cuando Warhol presentó su obra Brillo Box e hizo colapsar el parecido con un objeto cotidiano y banal no-obra de arte. Esto forzó la formulación correcta de la pregunta por el arte que dejó de ser la tradicional indagación acerca de ¿qué es el arte? en procura de su esencia para dar lugar al modo adecuado. Este es, ¿qué diferencia a una obra de arte de algo que no lo es, pero que sostiene respecto de ello una mismidad indiscernible?

Sea como sea, y puesto que la respuesta a dicho interrogante vendrá dada desde el ejercicio de la reflexión ocupada del tema, la definición del arte será filosófica. De este modo, la motivación del desarrollo del arte en su devenir histórico encuentra su fundamento en el progresivo reconocimiento de sí mismo hasta alcanzarlo en la propuesta filosófica. De manera tal que el supuesto cierre o finalización del desarrollo histórico, cifrado en su tesitura que postula el fin del arte supone el arribo a una definición de naturaleza filosófica, universal, intemporal y esencialista de sí. La adecuada comprensión del vínculo entre los tres momentos nucleares del planteo dantiano -esencialismo, historicismo, pluralismo-, con eje en el análisis de los casos de aparente indistinción, permitirá defender una lectura del mismo con acento en la diferencia, a la vez que una visión global del mismo.

Todo el esfuerzo de Danto estará, entonces, enfocado en dar con la diferencia específica que permita identificar uno de sus 
opuestos como arte. Tal búsqueda se compromete con la idea de que el arte se discontinua de la vida y que es menester estar en posesión de la especificidad de aquel en virtud de su reconocimiento y legitimidad.

El historicismo dantiano se compromete con el supuesto de que el arte posee una esencia y que dicha esencia se despliega en el tiempo de desarrollo histórico para hacerse manifiesta una vez que el contexto lo hace posible. Esto ocurre, según Danto, cuando desde el impulso interior del modernismo se alcanzó un modo de representación que logró elevar el adecuado cuestionamiento sobre la naturaleza del arte, coincidente con los ejercicios del arte pop de mediados de siglo pasado. Si bien el hecho de que los candidatos dantianos pertenezcan a categorías distintas -aun luciendo exactamente iguales- posibilitó la formulación de la pregunta, al mismo tiempo, obturó la posibilidad de su respuesta. El arte, desde su propia lógica progresista, careció de las competencias reflexivas para dar respuesta a dicho interrogante.

La efervescencia propia de las primeras décadas del siglo $X X$ en materia de producción de obras y sucesión de estilos —vanguardias históricas- dejó entrever que el arte reclamaba su definición. Para Danto, cada propuesta vanguardista con su propio manifiesto marcó el ascenso de este impulso reflexivo desde el arte. Paralelamente, ello puso en evidencia que tal impulso no persiguió la reflexión sobre los objetos de la representación, sino que buscó problematizar la dinámica misma de la representación artística (Danto, 1998).

De tal modo, cada obra supondría una interrogación, desde la exploración de las posibilidades lingüísticas de cada estilo, sobre la verdadera naturaleza del arte. Ambos dominios -el estrictamente creacionista en materia de producción de obra y el reflexivo que ronda la creciente necesidad del arte en su legitimación de dichos ejercicios productivos - marcan el último estadio de la historia del arte en su ascenso por el conocimiento de sí. La historia del arte moderno es, desde este enfoque, la búsqueda de su propia definición y, con ella, de su esencia.

La existencia de un impulso cognitivo del arte a lo largo de su historia supone la persecución del conocimiento acerca de su naturaleza. Esto es, el arte que busca de diferentes maneras la certeza de sí (Danto, 1998). Consecuentemente, y de darse dicha constatación, el arte devendría autoconsciente. Tal instancia es la que posiciona a Danto como un teórico de la mismidad, cifrada en el parecido extremo entre dos cosas cuando una de ellas supone participar del mundo del arte.

El punto de partida es una aparente indiscernibilidad entre cosas (mismidad). El par Brillo Box y Caja de Brillo no se diferencian 
en sus aspectos y, sin embargo, son cosas distintas que ejecutan funciones diferentes. Todo el restante esfuerzo por probar la otredad de una cosa sobre la restante (diferencia) supone el punto de partida del análisis y la configuración de una filosofía genuina del arte, según Danto. En sus tempranos ejercicios, su lectura partió del problema coyuntural de los indiscernibles para sostener que lo que sea que haga de uno de ellos una obra de arte no se correspondería con ningún set de propiedades estéticas visiblemente manifiestas. Por el contrario, sería su participación en un contexto imperceptible de legitimación al que denominó mundo del arte [artworld] el que estaría validando su inclusión en el universo de lo artístico (Danto, 1964).

La mismidad fuerza la diferencia. La imposibilidad de establecer dicha diferencia a nivel de la apariencia estética de los candidatos en cuestión promueve la búsqueda de la misma en el plano del análisis filosófico. Aún más, establece que dicha diferencia se vea cifrada en la captura de las propiedades específicas que algo debe poseer de manera necesaria y suficiente para que se vea reconocido como arte. Esto es, se compromete con una definición esencialista del arte. Si aquello que distinga una cosa de la otra no puede realizarse en términos de sus apariencias sensibles, deberá darse un viraje a nivel de la reflexión conceptual y el plano de las interpretaciones.

El esencialismo de Danto, entonces, es uno cuyos candidatos a esencia descansan sobre el dominio del análisis semántico. No se trata de propiedades que necesaria y suficientemente se encuentren entre las características físicas de las cosas u objetos, sino que suponen competencias a las que estos dan lugar como instancias de referencialidad semántica. Para que algo sea una obra de arte deberá poseer a) un contenido (aboutness) o sentido y b) deberá encarnar su significado (embodiment) (Danto, 1981).

La presencia y participación de ambas propiedades ( $a$ y $b$ ) aseguran la existencia de una obra de arte en todo tiempo posible, según lo requiere un esencialismo como el que se pretende aquí. Con esto, el autor habría arrojado la esperada definición del arte al mismo tiempo en que se habría clausurado el impulso cognitivo propio de éste. Si tal cosa se sostiene, y siguiendo su programa teórico, la historia del arte habría alcanzado una instancia de acabamiento o cierre.

No obstante, los candidatos a esencia dantianos ( $a$ y $b$ ) ofrecen no pocos motivos de crítica. Posiblemente, incluso, no sean lo

6 Para una lectura acerca de las críticas al esencialismo dantiano, véase Gerard Vilar (2005). exitosos que se espera al momento de cifrar, en la economía de sus expresiones, la naturaleza del fenómeno artístico. ${ }^{6}$ Sin embargo, y ateniéndonos al desarrollo de su propuesta, de haberse conseguido la definición se habría acabado la historia del 
7 Para una lectura acerca de las críticas a la tesis del «fin del arte» dantiana, véase Sondra Bacharach (2002), David Carrier (1998) y Nöel Carroll (1998). arte - siempre que la misma sea coincidente con el pretendido impulso cognitivo-. ${ }^{7}$ Tal parece ser el escenario en que el propio Danto desarrollara su labor filosófica. Un arte que alcanza el reconocimiento de su propia identidad mediante la captura de su esencia definicional.

El desarrollo de la historia del arte procuró, así, la generación de las condiciones necesarias para que la adecuada reflexión filosófica proveyera su definición. La indiscernibilidad que promovió dichas condiciones fue el producto de una prolongada búsqueda desde el interior mismo del arte y de sus lenguajes que experimentó y cuestionó su propia naturaleza. Brillo Box, de Warhol, supuso el punto culmine de un desarrollo cognitivo que procuró la autoconciencia para el arte. Ambas cajas no eran idénticas. Su diferencia, a pesar del molesto parecido, no era una diferencia en cuanto a sus apariencias. La Caja de Brillo (supermercado) responde a una lógica por entero diferente que la vincula de manera directa con el universo comercial de la sociedad neoyorquina de los sesenta. Brillo Box, por su parte, participa de a) y b), y esto la vuelve la obra de arte que es.

Más allá de los cuestionamientos que se alzaron y que pueden promoverse a partir de lo expuesto en este enfoque, el mismo es coherente con sus postulados básicos que presagiaron tanto el fin de la historia del arte como el arribo a una instancia democráticamente inclusiva de las formas y de los estilos artísticos. Lo primero es consecuencia de la estructura interna de su planteo - por equivocado que sea-; lo segundo, el resultado de una liberación: aquella que imponía modos específicos de producción de obra artística. El escenario actual del arte configura lo que en términos dantianos se conoce como la etapa pluralista, coincidente con su ingreso en la poshistoria.

De este modo, el pluralismo dantiano supone la consecuencia del cumplimiento de su programa teórico. Marca el momento en que el arte se liberó del imperativo de la búsqueda por su definición y la apertura de libertad potencialmente absoluta para el desarrollo de sus formas. El impulso progresista sostenido por el arte a lo largo de su historia se cancela justo en el momento en que este alcanza una definición sustantiva de sí. Esto permite no solo que la historia del arte llegue a su fin, sino que su ejercicio de cara al futuro participe de una ausencia de imposiciones y direcciones estilísticas. Desligado de la función de perseguir su esencia - puesto que dicha tarea compete a la filosofía - el universo de las formas del arte se expande hasta volverse absolutamente plural (Danto, 1998).

El pluralismo artístico es, así, el inevitable destino que encuentra el devenir arte del arte toda vez que él mismo ha alcanzado 
su definición. Esta, dado su carácter general y abarcador, cancela todo intento por establecer nuevas imposiciones que regulen cómo debe hacerse el arte en lo sucesivo. Ya no habrá narrativa que legitime su ejercicio porque el arte ha ingresado en una etapa de disolución de toda narrativa. En este sentido puede afirmarse, siguiendo a Danto, que la historia del arte marcó el impulso por alcanzar su libertad; libertad que una vez alcanzada erradicó para siempre la posibilidad de establecer criterios estilísticos que gobiernen la producción de obra y permitió, de esta manera, la coexistencia múltiple de formas y de estilos.

El programa filosófico de Danto en torno al arte parte de una instancia de aparente indistinción marcada por la lógica de homólogos indiscernibles. Según su enfoque, si el arte no logra distinguirse del resto de cosas, objetos y situaciones que configuran la trama de la vida cotidiana, el resultado obtura la identificación $y$, consecuentemente, anula su posibilidad. Por lo tanto, su tarea se compromete decididamente con la captura de la diferencia en cuestión. Una vez que se pudo diferenciar entre ambas cajas, las consecuencias dieron lugar a los ejes que aqui se analizaron: historicismo, esencialismo y pluralismo.

La complejidad de este planteo teórico supone la necesidad de dar con dicha diferencia. Danto no estaba obsesionado con la insoportable semejanza entre ambas cajas, sino con encontrar la diferencia existente que no se deja ver a simple vista. Ante esto, podría sostenerse que su lectura acerca de la historia del arte como el desenvolvimiento de los distintos modos de experimentación desarrollados en procura de su propio conocimiento -impulso cognitivo- respondería, mejor, a la figura de una resistencia cronológica por hacerse de la diferencia y no colapsar contra el fondo de vida que subyace a sus ejercicios. El arte, así considerado, no persiguió su autoconocimiento como historia, sino que se aferró a la diferencia que hizo posible su identificación.

\section{Consideraciones finales}

Ambas cajas se encuentran ubicadas una al lado de la otra. Luce, cada una, exactamente igual que su par. Una de ellas es un simple envoltorio del producto comercial que llena su contenido (jabón). La otra es una de las obras de arte más polémicas del siglo XX después de los experimentos vanguardistas que le dieron origen. El conflicto se genera al nivel de las percepciones pero inquieta en la comprensión. La dificultad estriba en reconocer, a simple vista, cuál de ambas cajas se corresponde con la descripción esbozada. 
La pregunta que anima este último tramo del escrito inquiere acerca de la relación entre diferencia y mismidad. En términos generales, cabe preguntar ¿por qué nos empecinamos en priorizar lo general por sobre las múltiples diferencias particulares? Si bien a la distancia perceptual ambos objetos se muestran indistinguibles, analizados detenidamente y de cerca el parecido comienza a desdibujarse. Uno de ellos ofrece una estructura de cartón cuidadosamente diseñada en sus detalles estéticos y sus colores porque responde a una lógica mercantil que busca motivar al acto de la compra. El otro, presenta una superficie enchapada en cuyo interior no hay nada. El primero de estos objetos fue diseñado por James Harvey como estrategia publicitaria de un producto comercial; mientras que el segundo fue pergeñado por Andy Warhol, con posterioridad, con el propósito de celebrar desde el arte la sociedad de consumo neoyorquina de los sesenta y con el afán de proveer nuevas experiencias sensibles, pero de ningún modo motivar el consumo de jabones. En este primer acercamiento descriptivo ya se observan más diferencias que similitudes entre ambos objetos.

Hay en pugna dos concepciones de la diferencia: una que sustrae las diferencias de lo mismo, en la que lo mismo es fundamento de la diferencia. Y otra, en la cual, inversamente, las diferencias constituyen el fundamento sobre el cual se construye lo mismo. Es decir, lo mismo se sustrae. En un caso se privilegia la mismidad por sobre las diferencias, mientras que en otro caso, la diferencia es soberana. En este sentido último, lo diferente se instituye como requisito a partir del cual al arte irrumpe como aquello que se discontinúa de lo mismo y no cesa de renovar la problemática por su naturaleza.

Bajo esta renovada lectura, Brillo Box es un compendio de diferencias que se sostiene, en un caso, sobre el trasfondo histórico que arrojará la distinción esencial, en el otro, desde la presencia misma que constituye la compleja unidad de cada obra. La Caja de Brillo, por su parte, también asume la complejidad de una unidad plena de diferencias, diferentes a su vez de las anteriores. La primera, pero no la segunda, promoverá asociaciones y sensaciones disímiles y capturará sentidos y valores renovados. La segunda, aunque no la primera, fijará asociaciones determinadas y concretas circunscriptas al ámbito mercantil. Tal disparidad se fundamenta en el desarrollo de funciones diferentes.

El recorrido del presente escrito no buscó motivar una interpretación homogénea de los autores trabajados. Sabemos que cada uno de estos pertenece a tradiciones filosóficas bien diferenciadas. No obstante, proyectos intelectuales dispares pueden proyectar aciertos frente a una problemática común. En 
este sentido, no se pretende yuxtaponer filosofías contrapuestas bajo un mismo abarque conceptual, sino articular dos posiciones en un núcleo problemático. La alternativa de solución que se promueva desde cada uno de estos enfoques bien puede sostenerse en la discrepancia. Esto es, ambas posiciones no tienen por qué comprometerse con el acuerdo entre sí. Desde aquí es posible pensar en planteamientos problemáticos divergentes con soluciones, consecuentemente distintas. Ambos autores recuperan la diferencia como elemento fundamental de la configuración artística, que se actualiza con cada obra en cada caso. Esto, y no otra cosa, motivó el desarrollo del presente ensayo.

\section{Referencias}

Bacharach, S. (2002). Can art really end? The Journal of Aesthetics and Art Criticism, 60(1), 57-66.

Carrier, D. (1998). After the end of art and art history. History and Theory, $37(4), 1-16$.

Carroll, N. (1998). The end of art? History and Theory, 37(4), 17-29.

Danto, A. (1964). The Artworld. The Journal of Philosophy, 61(19), 571-584.

Danto, A. [1981] (2004). la transfiguración del lugar común. Buenos Aires, Argentina: Paidós.

Danto, A. (1998). The End of art: A Philosophical Defense. History and Theory, 37(4), 127-143.

Deleuze, G. (1970). Proust y los signos (Trad. Francisco Monge). Barcelona, España: Anagrama.

Deleuze, G. (2008a). Lógica del sentido (Trad. Miguel Morey y Victor Molina). Barcelona, España: Paidós.

Deleuze, G. (2008b). Nietzsche y la filosofía (Trad. Carmen Artal). Barcelona, España: Anagrama.

Deleuze, G. (2009a). Diferencia y repetición (Trad. María Silvia Delpy y Hugo Beccacece). Barcelona, España: Amorrortu.

Deleuze, G. (2009b). Francis Bacon. Lógica de la sensación, Madrid, España: Arena Libros.

Deleuze, G. (2013). Diálogos (Trad. José Vázquez Pérez). Valencia, España: Pre-Textos.

Deleuze, G. (2014). Conversaciones. 1972-1990. (Trad. José Luis Pardo). Valencia, España: Pre-Textos.

Deleuze, G. y Guattari, F. (2006). Mil mesetas. Capitalismo y esquizofrenia. (Trad. José Vázquez Pérez y Umbelena Larraceleta). Valencia, España: Pre-Textos. 
Deleuze, G. y Guattari, F. (2009). ¿Qué es la filosofía? (Trad. Thomas Kauf). Barcelona, España: Anagrama.

Kennick, W. (1958). Does Traditional Aesthetics Rest on a Mistake? Mind, (67), 317-34.

Scherér, R. (2012). Miradas sobre Deleuze (Trad. Sebastián Puente). Buenos Aires, Argentina: Cactus.

Vilar, G. (2005). Las razones del arte. Madrid, España: Visor.

Warhol, A. (1964). Brillo Box [Objeto]. Recuperado de https://www. moma.org/collection/works/81384

Weitz, M. (1956). The Role of Theory in Aesthetics. Journal of Aesthetics and Art Criticism, 27-37.

Wittgenstein, L. [1953] (2008). Investigaciones filosóficas. Barcelona, España: Crítica.

Ziff, P. (1953). The Task of Defining a Work of Art. The Philosophical Review, (62), 58-78. 